Quebec Cooperative Study

of Friedreich's Ataxia

\title{
Cardiovascular Evaluation of Obligate Heterozygotes in Friedreich's Ataxia
}

\author{
M. COTE, A. LAROSE, M.CIMON AND B.LEMIEUX
}

SUMMARY: A study of 17 parents (obligate heterozigotes) of children with Friedreich's ataxia was carried out. In addition to medical histories and phisical examinations, a standard 12 lead ECG tracing was obtained. In the age group below' 50, there was no significant evidence of ischaemic or primary cardiomy'opathy. Older subjects had more frequent risk factors for arteriosclerotic heart disease.

RÉSUMÉ: Nous présentons une étude faite che 17 parents (hétérozl'gotes obligatoires) d'enfants atteints d'ataxie de Friedreich. En plus de l'anamnèse et d'un examen médical nous avons enregistré chez ces sujets un électrocardiogramme standard à 12 conduits. Chez les moins de 50 ans, nous n'avons trouvé aucune évidence de cardiomyopathie ischémique ou primaire. Chez les sujets plus âgés on note une incidence plus élevée des facteurs de risque pour la maladie cardiaque artériosclérotique.
From the Centre Hospitalier Universitaire de Sherbrooke, Sherbrooke, Québec.

Reprint requests for the complete supplement on Friedreich's ataxia (Phase Two; Part Two) to:

Dr. André Barbeau, Clinical Research Institute of Montreal, 110 Pine Avenue West, Montreal, Quebec. H2W IR7.

\section{INTRODUCTION}

Classical Friedreich's ataxia is considered to be an inherited autosomal recessive disorder (Barbeau, 1976; Andermann et al., 1976). The cardiomyopathy associated with Friedreich's ataxia, one of the hallmarks of the disease, is evidenced by abnormal physical findings, and frequent electrocardiographic, echocardiographic, and hemodynamic abnormalities that suggest a hypertrophic cardiomyopathy of varying severity, occasionally obstructive (Thoren, 1964, Quebec Cooperative Study, 1976).

Some controversies exist, however, concerning the incidence of cardiac disorders afflicting obligate heterozygotes, the parents of individuals suffering from Friedreich's ataxia. Thoren (1964) examined 26 parents under 50 years of age and did not find an abnormally high incidence of ischaemic heart disease or cardiomyopathy. Only two of the parents had an abnormal E.C.G. Andermann et al. (1976), on the other hand, in an evaluation of 24 parents from a retrospective study, documented E.C.G. abnormalities in 77 percent of fathers and 33 percent of mothers. The present study was undertaken to determine the prevalence of cardiac abnormalities in parents of some of the patients involved in the prospective Quebec Cooperative Study of Friedreich's ataxia (1976).

\section{CASE MATERIAL AND METHODS}

The parents from ten families with children afflicted with Friedreich's ataxia were included in this study. Seven families had two or more children with the disease. All ten mothers and seven fathers were examined. The three unavailable fathers are alive and enjoying good health. The medical history, physical findings, and a standard 12 lead E.C.G. tracing of the seventeen parents were analysed.

\section{RESULTS}

\section{a) Medical history and} phy'sical findings:

The age of the 17 parents varied from 28 to 60 years (median age 44 ), nine being 50 or over. Personal medical history and physical examination was normal in eight parents, two of these were over 50 years. (Table 1). Nine parents had an abnormal medical history or abnormal physical findings. Two of these were less than fifty years of age. Case 8, a twenty-eight year old female, had suffered from Crohn's disease since the age of twenty and had surgery for a cervical carcinoma in situ. Case 2, a forty nine year old male suffered from incapacitating angina and significant arteriosclerotic heart disease documented by coronary angiography. His resting E.C.G. was normal. He also suffered from glaucoma.

In the seven remaining abnormal parents, aged fifty or more, four suffered from essential hypertension, four from chronic obstructive pulmonary disease due to smoking. The two conditions co-existed in two parents. Only one of the parents was thought to have arteriosclerotic heart disease other than case 2 described above. Aged 55, he suffered from severe emphysema, hypertension, and obesity (case 14). His resting E.C.G. was compatible with myocardial ischemia; he also had a persistant fasting hyperglycemia and hypertriglyceridemia. 
TABLE 1

\begin{tabular}{clllll}
\hline Case No. & & Age & Sex & History and physical examination & E.C.G. \\
\hline 1 & & & & & N \\
2 & C.P. & 39 & F & Normal & N \\
3 & D.G. & 49 & M & Angina - glaucoma & ABN \\
4 & D.R. & 46 & F & Normal & N \\
5 & F.R. & 35 & M & Normal & N \\
6 & F.M. & 32 & F & Normal & N \\
7 & F.C. & 51 & F & Normal & N \\
8 & G.R. & 33 & M & Normal & N \\
9 & G.H. & 28 & F & Crohn's Disease Cervical Ca. in situ & ABN \\
10 & H.D. & 56 & M & Raynaud's Phenomenon - Alcoholism & N \\
11 & H.O. & 54 & F & Hypertension & ABN \\
12 & L.H. & 53 & M & Chronic Bronchitis & ABN \\
13 & L.G. & 48 & F & Normal & N \\
14 & M.F. & 60 & F & Hypertension - Depression & N \\
15 & M.G. & 55 & M & Hypertension - Emphysema - Obesity & N \\
16 & T.P. & 58 & F & Chronic Bronchitis - Diabetic Neuropathy & Chronic Bronchitis - Labile Hypertension \\
17 & T.M. & 55 & F & Normal & \\
\hline
\end{tabular}

$$
\begin{array}{ll}
\mathrm{N}-\text { Normal } & \mathrm{F}-\text { Female } \\
\text { ABN }- \text { Abnormal } & \mathrm{M}-\text { Male }
\end{array}
$$

Evidence of diabetes mellitus was found in only one other parent (case 15), she suffered from chronic bronchitis and diabetic neuropathy. Her glucose tolerance curve was compatible with diabetes mellitus. One father (case 9) was an alcoholic and suffered from Raynaud's disease. Cardiovascular disease was found in five parents (29 percent), four with hypertension and one with coronary insufficiency. Two parents (11 percent) had maturity onset diabetes.

\section{b) Electrocardiogram:}

The electrocardiograms of thirteen parents were normal, including the resting E.C.G. of Case 2, the only parent with documented coronary artery disease. The electrocardiograms of four parents (24 percent) were abnormal, two showed a slight conduction abnormality. A 46 year old mother's E.C.G. depicted left anterior hemiblock (case 3). She had a normal medical history and physical examination. The other (case 10) had a slightly prolonged $P R$ interval of 0.22 seconds. She suffered from hypertension and was receiving diuretics.

The E.C.G. abnormalities of the others consisted of ST-T wave changes: non specific flattening of the $T$ waves in case 13 that could be explained by her hypertension with diuretics and phenothiazines received for depression; and "Ischaemic" $T$ wave changes in case 14 , clinically incapacitated mainly by severe emphysema and moderate hypertension.

\section{DISCUSSION}

The clinical and E.C.G. studies of parents of Friedreich's ataxia patients were performed to evaluate the prevalence of cardiovascular abnormalities. The analysis of the results of the albeit small group of parents aged fifty or less does not show an abnormally high prevalence of premature onset of arteriosclerotic heart disease. In this group, however, a 49 year old father was the only one with documented coronary artery disease.

The presence of left anterior hemiblock on the E.C.G. tracing of a 46 year old asymptomatic mother remains unexplained. A genetic factor has been implicated with this E.C.G. anomaly which may be found in 5 percent of adults (Siegman-Igra, 1978). Another genetically linked disorder, Crohn's disease, was present in a twenty-eight year old mother but to our knowledge an association between this disease and Friedreich's ataxia has not been reported.

In the group of nine parents aged fifty or more, symptomatic ischaemic heart disease was not present but essential hypertension was found in four, almost half of that age group (23 percent overall), a prevalence somewhat higher than the 25-30 percent prevalence of hypertension in the 50 and older age group (Kennel, 1970). Other coronary-risk factors were also frequent with smoking and chronic pulmonary lung disease in four and adult onset diabetes in two.

Three E.C.G. tracings in the fifty years and older group were abnormal, all in hypertensives and some taking medications such as phenothiazines known to produce E.C.G. abnormalities. These abnormalities could be considered secondary to these factors rather than indications of a primary cardiomyopathy.

Our results would support the conclusion of Thoren (1964) that there does not appear to be a premature or abnormally high incidence of cardiomyopathy, whether ischaemic or primary, in parents of children with Friedreich's ataxia. In our older age group, however, seven of nine parents presented with one or more risk 
factors known to accelerate the development of arteriosclerotic heart disease such as hypertension, smoking, and diabetes mellitus.

\section{ACKNOWLEDGEMENTS}

This study was supported in part by l'Association Canadienne de l'Ataxie de Friedreich. We would like to recognize the able assistance of $G$. Plourde, $R N$ and $J$.

Fortin, RN.

\section{REFERENCES}

ANDERMANN, E., REMILLARD, G. M GOYER, C., BLITZER, L., ANDERMANN, F. and BARBEAU, A. (1976). Genetic and family studies in Friedreich's ataxia. Can. J. Neurol. Sci. 3: 287-301.

BARBEAU, A. (1976). Friedreich's ataxia - an overview. Can. J. Neurol. Sci. 3: 389-397.

KENNEL, E. B., WOLF, P. A., VORTER, J. and McNAMARA, P. M. (1970). Epidemiologic assessment of the role of blood pressure in stoke. JAMA $214-301-310$.
Quebec Cooperative Study of Friedreich's Ataxia (1976). Can. J. Neurol. Sci. 3: 319342.

SIEGMAN-IGRA，Y., YAHMI, J. H., GLOBOURT, U., NEUFELD, N. H. (1978). Intraventricular conduction disturbances. Amer. Hosp. J. 96: 669-679.

THOREN, C. (1964). Cardiomyopathy in Friedreich's ataxia: with studies of cardiovascular and respiratory functions. Acta Paediatrica (Suppl.) 53 (153): 1-132. 